\title{
Kadın Basketbol ve Voleybol Sporcularının Bass Stick Lenghtwise ve Crosswise Denge Testi Karşılaştırması
}

\section{Comparison of Bass Stick Lengthwise and Crosswise Balance Test of Women Basketball and Volleyball Athletes}

\author{
ORIJJINAL ARAŞTIRMA \\ ORIGINAL RESEARCH \\ Cenab TÜRKERI ${ }^{1 \dagger}$, \\ Elif $\mathrm{AKYOL}^{2}$, \\ Bilgihan BÜYÜKTAŞ3 ${ }^{3}$, \\ Barışcan ÖZTÜRK ${ }^{4}$,
}

${ }^{1}$ Çukurova Üniversitesi, BESYO, Adana, https://orcid.org/0000-0003-4850-9810 ${ }^{2}$ Çukurova Üniversitesi, BESYO, Adana, https://orcid.org/0000-0002-0526-6647 ${ }^{3}$ Çukurova Üniversitesi, Sağlık Bilimleri Enstitüsü, Adana https://orcid.org/0000-0002-6816-7275 ${ }^{4}$ Çukurova Üniversitesi, Sağlık Bilimleri Enstitüsü, Adana https://orcid.org/0000-0001-7001-3032

\section{Öz}

$\mathrm{Bu}$ çalışma Basketbol ve voleybol spor branşlarında yarışmalara katılan kadın sporcuların statik denge becerisinin Bass Stick Lengthwise ve Bass Stick Crosswise testi ile karşılaştırılması amacıyla yapılmıştır. Araştırma Adana ilinde spor yapan, branșlarında (basketbol ve voleybol) en az 1 yıllık geçmișe sahip yașları 12,38 1 1,46 y1l, boylar1 $159,32 \pm 10,41 \mathrm{~cm}, 50,84 \pm 10,67 \mathrm{~kg}$ olan toplam 167 kadın sporcu üzerinde yürütülmüştür. Çalışmadan elde edilen bulgular doğrultusunda; branşlara göre Lengthwise ve crosswise statik denge ölçüm değerleri arasında anlamlı bir farklılık bulunmuștur. Branșlara göre her iki statik denge testinde de farklılığın basketbol branşından kaynaklandığ 1 bulunmuştur $(\mathrm{p}=0,00)$. Haftalık antrenman saati ile Lengthwise $(r=0,647)$ ve crosswise $(r=0,339)$ statik denge değerleri arasında pozitif yönde anlamlı bir ilişki bulunmuştur $(\mathrm{p}=0,00)$. Sonuç olarak, ikili mücadele ve fiziksel temas içeren basketbol sporcularının statik denge becerilerinin fiziksel temas içermeyen voleybol sporcularından daha iyi olduğu, voleybol sporu yapan sporculara normal antrenmanlarına ek olarak farklı yüzeylerde, yumuşak zeminlerde ve fiziksel temasların da bulunduğu denge çalışmaları yapmalarının statik dengelerini geliştirebileceği söylenebilir.

Anahtar Kelimeler: Bass Stick Lengthwise - Crosswise Denge Testi, Statik Denge, Voleybol, Basketbol.

\begin{abstract}
The aim of this study was to compare the static balance ability of female athletes participating in competitions in basketball and volleyball sports with Bass Stick Lengthwise and Bass Stick Crosswise tests. Research A total of 167 women who are active in sports in Adana and have at least one year of history in their branches (basketball and volleyball) are 12.38 \pm 1.46 years, $159,32 \pm 10,41 \mathrm{~cm}$ and 50,84 $\pm 10,67$ $\mathrm{kg}$ athletes. According to the findings obtained from the study, a significant difference was found between Lengthwise and crosswise static balance measurement values according to the branches. According to the branches, the difference in both static balance tests was found to be due to the basketball branch $(\mathrm{p}=0,00)$. There was a positive correlation between weekly training time and Lengthwise $(r=0.647)$ and crosswise $(r$ $=0.339)$ static balance values $(\mathrm{p}=0,00)$

As a result, static balance skills of basketball athletes that involve mutual struggle and physical contact were found to be better than those of volleyball athletes that do not involve physical contact. It can be said that athletes who play volleyball sport can improve their static balance by performing balance exercises on different surfaces, soft floors and physical contacts in addition to their normal training.
\end{abstract}

Keywords: Bass Stick Lengthwise-Crosswise Balance Test, Static Balance, Volleyball, Basketball.

\footnotetext{
+ Sorumlu yazar: Cenab Türkeri, cturkeri@cu.edu.tr
} 


\section{GİRIŞ}

Sporda başarıya ulaşmak ve bunu koruyabilmek için fiziksel, fizyolojik ve psikolojik oldukça fazla parametre bulunmaktadır. Antrenörün amacı, sporcunun branşına yönelik geliştirilmesi gereken özelliklerin neler olduğunu tespit etmek ve bunları uygun aralıklarla test ederek sonuçlarına göre plan program hazırlamak ve takibini yapmaktır. Sporcuların temel amacı; fiziksel uygunluklarını geliştirerek ve koruyarak sportif başarılarını devam ettirmektir (Zorba ve ark., 2013). Bu doğrultuda sporcular mentör, antrenör ve kondisyoner ile birlikte çalışarak gerek yarışma dönemi antrenman, gerekse geçiş dönemlerindeki antrenman planlarında eksik olan parametreleri tamamlamakta veya mevcut performanslarını arttırmaya yönelik çalışmalarda bulunmaktadır. Temel motorik özelliklerin gelişiminin yanı sıra destekleyici özelliklerin de gelişimi sporcuların performanslarını pozitif yönde etkilemektedir. Önemli unsurlardan birisi olan denge özelliği sporcuların antrenman ve müsabaka esnasında yapacakları hareketleri daha doğru sergilemesinde vazgeçilmez bir faktördür. Takım oyunlarındaki ani duruş, yer ve yön değiştirmeler, hızlanmalar, çeşitli disiplinlerde rahatsız edici etkilere karşın hareketlerin sürdürülmesi denge gerektirir. Birçok spor dalındaki eller, ayaklar veya ayak üzerindeki kısa ya da uzun süreli duruşlar veya hareketler, değişik yönlere ve eksenler etrafındaki dönüşler bu yeteneği gerektirir (Sayın, 2011). Geniş bir alanda devamlı ileri ve geri hızlı-yavaş koşular, ani yön değiştirmeler, sıçrama ve uzanmalar, geri, ileri ve yanlara top sürmeler, firlatılan bir topu tutma, saklama, kontrol etme ve yön değiştirerek firlatmaların olduğu basketbol sporu ile dar bir alanda yana, ileri ve geri ani kısa adımlamalar, tekrarlayan yüksek sıçramalar, yere doğru ani ve uzun uzanmalar (plonjon), şiddetli topa vuruş ya da karşılamaların olduğu voleybol sporunda denge yetisi oldukça önemlidir.

Son yıllarda denge egzersizlerinin antrenman programlarındaki yeri ve atletik performans arttırmadaki rolü ve önemi giderek artmaktadır. Bunu dinamik ve statik denge üzerine yapılan araştırmaların sayısının artmasından da anlamaktayız. Denge performansı ve spor ilişkisi, birçok spor branşı üzerinde yapılan çalışmalarla ortaya konulmaktadır. Yapılan araştırmalarla, üst düzey sporcuların başarılı olmaları için gereken fiziksel, fizyolojik ve psikolojik değerler tanımlanmaya çalışılmaktadır. $\mathrm{Bu}$ araştırmalara göre, antrenman ve müsabakalarda yüksek seviyede motor hareketlerin yapılması, hem statik hem de dinamik dengenin kontrolünde etkilidir. Göreve en uygun duyusal-motor stratejinin seçimi ve zihinsel yetenekler, sporcuların özellikle eğitim 
esnasında kazandıkları duyusal bilgiye dayanır (Sucan, Yılmaz, Can ve Süer, 2005). Üst düzey sporcuların, her bir disiplinin gerekleriyle bağlantılı olarak gelişen denge kontrolü sergiledikleri belirtilmektedir (Erkmen, Suveren, Göktepe ve Yazıcıoğlu, 2007). Denge hem bulunulan bir pozisyonun korunmasını hem de bu konumdan başka bir konuma geçmek için yapılacak teknik veya motorik hareketin akıcılığını, doğruluğunu, keskinliğini kısaca ortama uygunluğunu oluşturmada en önemli parametrelerden birisidir.

Literatür incelendiğinde, statik denge ile ilgili birçok çalışma bulunmaktadır. Ancak, çalışmalar genelde statik dengeyi tek bir test ile ölçerek yapılmıştır (Erdoğan ve ark., 2017; Sökmen ve Arslanoğlu 2013; Tetik, M. Koç, Atar ve H. Koç, 2013). Birden fazla test kullanılarak statik denge ölçümü yapılan çalışma çok az sayıda bulunmaktadır (Bressel, Yonker, Kras ve Heath, 2007). Denge özelliğinin spor branşlarına göre kendi aralarında nasıl farklılıklar gösterdiği araştırılması gereken önemli bir konudur. Denge özelliği dinamik ve statik olarak iki farklı başlık altında araştırılmaktadır. Ancak zorluk derecesi farklı iki statik denge testi ile spor branşları arasındaki farkın incelendiği literatüre rastlanmamıştır.

Bu bağlamda bu araştırma, basketbol ve voleybol spor branşlarında yarışmalara katılan sporcuların statik denge becerisini zorluk dereceleri birbirinden farklı Bass Stick Lengthwise ve Bass Stick Crosswise testi ile karşılaştırarak literatüre katkı sağlaması amacıyla yapılmıştır.

\section{YÖNTEM}

\section{Çalışma Grubu}

Çukurova Üniversitesi, BESYO, Performans Ölçüm Laboratuvarında yapılan çalışmaya, herhangi bir yaralanması olmayan, branşında en az bir yıllık spor geçmişine sahip, yaş ortalamaları $12,38 \pm 1,46$ yıl, boy ortalamaları $159,32 \pm 10,41 \mathrm{~cm}$, ağırlık ortalamaları $50,84 \pm 10,67 \mathrm{~kg}$ olan (voleybol, n=108 ve basketbol, n=59) toplam 167 kadın sporcu gönüllü olarak katılmıştır. Sporculara ve ailelerine çalışma protokolü hakkında bilgi verilmiş, kabul edenlere çalışmanın amaç ve yöntemlerini belirten onam formu imzalatılmıştır. Çukurova Üniversitesi girişimsel olmayan klinik araştırmalar etik kurulundan 04.09.19/91-69 karar numarası ile onay alındı. 


\section{Veri Toplama Aracı}

Genel değerlendirme formuna kişinin; yaş, boy, ağırlık, spor branş1, spor yaşı ve vücut kitle indeksi (BMI) kaydedilmiştir. Sporcunun hastalık, yaralanma, ameliyat varlığı, kullandığı ilaçlar, alerji ve beslenme durumları sorgulanmış ve kayıt altına alınmıştır. Sporcuların, denge ölçümünde kullanacakları dominant ayaklarını belirlemek amacıyla, bir topa vurmak için öncelikli olarak hangi bacağını kullanırsın sorusu yöneltilmiş ve baskın ve baskın olmayan ayakları belirlenmiştir.

Bass Stick Lengthwise Statik Denge Testi: Bass Stick Lengthwise Test yöntemi, $(2.5 * 2.5 * 30.5 \mathrm{~cm}$ ölçülerinde) tahta çubuk kullanılarak uygulanmıştır. Deneklere çubuğun uzun boyunca dominant ayakları üzerinde (ayak çıplak), eller serbest ve sabit olmayan bacağın ayağı sabit olan bacağa dokunacak şekilde durmaları söylenmiş ve deneklerin iki deneme yapmasına izin verilmiştir. Denge pozisyonu alındığı anda süre ölçer çalıştırılmış ve denek dengesini yitirip bıraktığında ya da bükülü ayağını yere değdirdiği anda süreölçer durdurulmuştur (Safrit ve Wood, 1995; Türkeri, 2014).

Bass Stick Crosswise Statik Denge Testi: Bass Stick CrosswiseTest yöntemi, $(2.5 * 2.5 * 30.5 \mathrm{~cm}$ ölçülerinde) tahta çubuk kullanılarak uygulanmıştır. Deneklere çubuğun enine kesiti üzerinde ayak pençesi (ball of foot) ile (ayak çıplak), eller serbest ve sabit olmayan bacağın ayağı sabit olan bacağa dokunacak şekilde durmaları söylenmiş ve deneklerin iki deneme yapmasına izin verilmiştir. Denge pozisyonu alındığı anda süreölçer çalıştırılmış ve denek dengesini yitirip bıraktığında ya da bükülü ayağını yere değdirdiği anda süreölçer durdurulmuştur (Safrit, 1995).

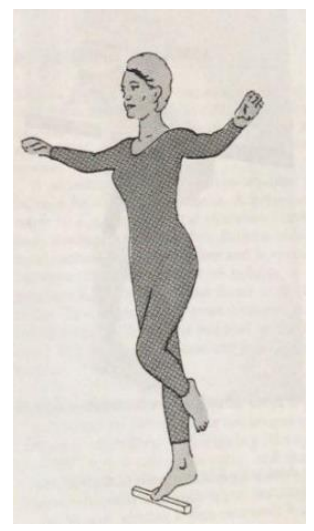

Şekil 1. Bass Stick Crosswise Testi 


\section{Verilerin Analizi}

İstatistiksel analizler, SPSS 21.0 programı kullanılarak yapılmıştır. Bireylerin demografik özellikleri tanımlayıcı istatistikler ile analiz edilmiştir. Sonuçlar, aritmetik ortalama \pm standart sapma ( $\overline{\mathrm{x}} \pm \mathrm{SS})$ olarak verilmiştir. Verilerin normal dağılımları için Kolmogorov- Smirnov testi sonuçlarına bakılmıştır. Veriler normal dağılım göstermediği için karşılaştırmalarda nonparametrik testlerden ikili karşılaştırmalarda; Mann Whitney U testi ve verilerin birbirleri ile olan ilişkilerini belirlemek için Spearman' Rho Korelasyon testi uygulanmıştır. İstatistiksel anlamlılık için $\mathrm{p} \leq 0,05$ olarak kabul edilmiştir.

\section{BULGULAR}

\section{Demografik Bulgular}

Tablo 1'de her biriyle ayrı yapılan görüşmelerle genel değerlendirme formuna kaydedilen sporcuların demografik özellikleri verilmiştir. Formda, kişinin; yaş, boy, ağırlık, spor branşı, spor yaşı ve vücut kitle indeksi (BMI) araştırıcı tarafından kaydedilmiştir. Çalışmaya katılan

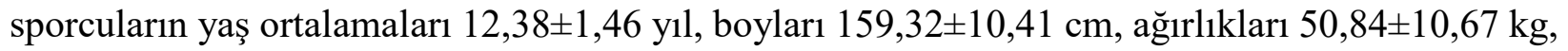
spor yaşları 2,72 $\pm 1,48$ y1l, haftalık antrenman saatleri 4,76 $\pm 2,00$ saat ve BMI 19,84 $\pm 2,67$ olarak bulunmuştur.

Tablo 1. Sporcuların Demografik Özellikleri

\begin{tabular}{lccr}
\hline $\mathbf{n = 1 6 7}$ & Min. & Mak. & $\overline{\mathbf{x}} \pm \mathbf{S S}$ \\
\hline Yaş (yıl) & 10,00 & 15,00 & $12,38 \pm 1,46$ \\
Boy (cm) & 137,00 & 185,00 & $159,32 \pm 10,41$ \\
Ağırlık (kg) & 30,00 & 78,00 & $50,84 \pm 10,67$ \\
Spor Yaşı (yıl) & 1,00 & 6,00 & $2,72 \pm 1,48$ \\
Haftalık Antrenman Saati & 3,00 & 9,00 & $4,76 \pm 2,00$ \\
BMI (kg/m ${ }^{2}$ ) Çalışmaya katılan sporcuların \%64,7'si (n=108) voleybol branşında ve \%35,3'ü (n=59)
\end{tabular}

basketbol branşında sporcudur. (şekil 2.). 


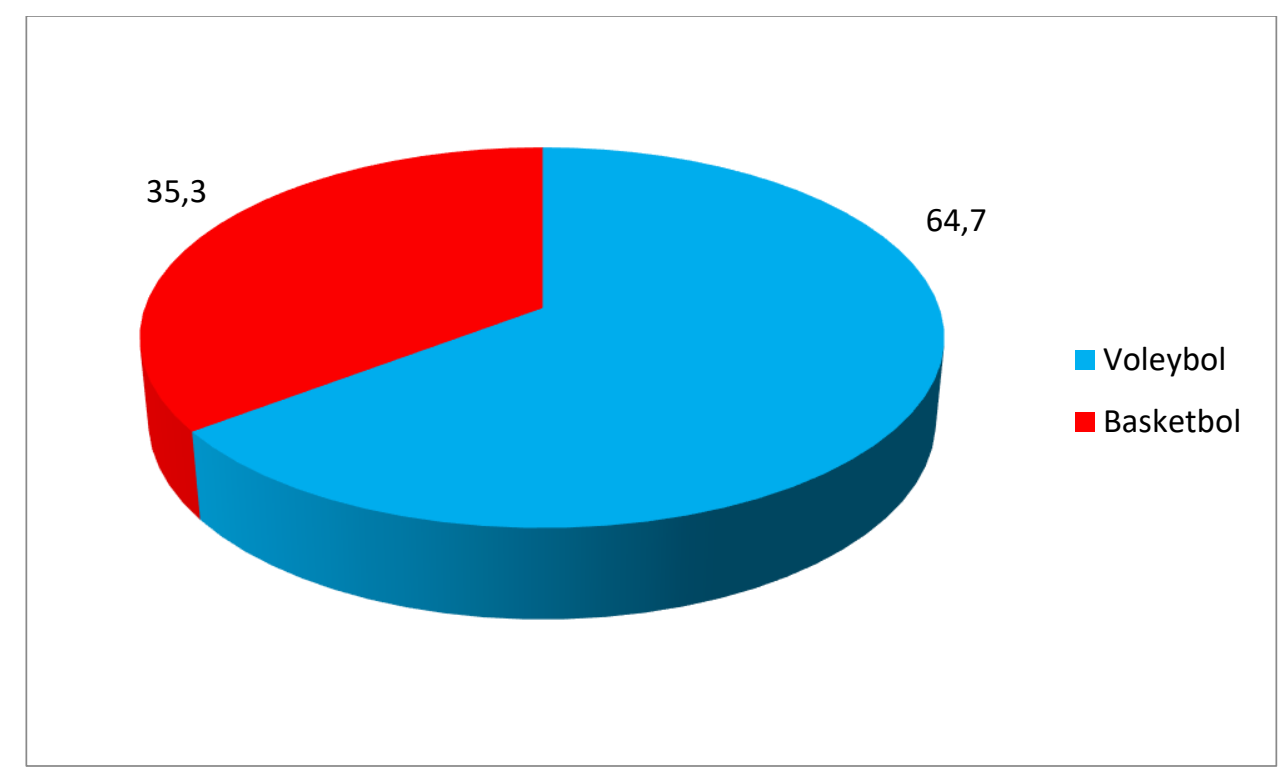

Şekil 2. Sporcuların Branşlarına Göre Dağılımı

\section{Denge ile İlgili Bulgular}

Tablo 2'de sporcuların branşlarına göre denge ölçümleri karşılaştırmaları verilmiştir. Katılan sporcuların spor branşlarına göre lengthwise ve crosswise statik denge değerleri arasında anlamlı bir farklılık bulunmuştur $(\mathrm{p}=0,00)$. Her iki statik denge testinde de farklılığın basketbol branşında yarışmalara katılan sporculardan kaynaklandığı görülmüş̧ür.

Tablo 2. Sporcuların branşlara göre lengthwise ve crosswise statik denge değerlerinin karşılaş̧ırması

\begin{tabular}{llccccc}
\hline & $\begin{array}{l}\text { Spor } \\
\text { Branşları }\end{array}$ & $\mathbf{n}$ & Sıra Ort. & $\overline{\mathbf{x}} \pm$ SS & $\mathbf{z}$ & $\mathbf{p}$ \\
\hline Lengthwise & Voleybol & 108 & 65,92 & $4,44 \pm 2,43$ & & \\
& Basketbol & 59 & 117,09 & $\mathbf{9 , 3 0 \pm 5 , 8 3}$ & & $\mathbf{0 , 0 0 *}$ \\
& Voleybol & 108 & 74,23 & $2,05 \pm 0,67$ & & \\
Crosswise & Basketbol & 59 & 101,88 & $\mathbf{2 , 6 6} \pm \mathbf{1 , 2 2}$ & & \\
\hline $\mathrm{p} \leq 0,05^{*}$ & & & & & &
\end{tabular}

Tablo 3'te tüm sporcuların haftalık antrenman saati ile lengthwise ve crosswise statik denge değerleri arasındaki ilişkileri verilmiştir. Sonuçlara göre haftalık antrenman saatleri ile lengthwise 
statik denge değerleri arasında orta düzeyde $(\mathrm{r}=0,647)$ bir ilişki bulunmuştur $(\mathrm{p}=0,00)$. Haftalık antrenman saatleri ile crosswise statik denge değerleri arasında düşük bir ilişki $(r=0,339)$ bulunmuştur $(\mathrm{p}=0,00)$.

Tablo 3. Tüm sporcuların haftalık antrenman saati ile bass stick lengthwise ve crosswise statik denge ilişkisi

\begin{tabular}{lcc}
\hline $\begin{array}{l}\text { Denge Testi } \\
\mathbf{n}=167\end{array}$ & \multicolumn{2}{c}{ Haftalık Antrenman Saati } \\
\hline Bass Stick Lengthwise & $\mathbf{0 , 6 4 7 ^ { * * }}$ & $\mathrm{p}$ \\
Bass Stick Crosswise & $\mathbf{0 , 3 3 9 ^ { * * }}$ & 0,00 \\
\hline
\end{tabular}
$\mathrm{p} \leq 0,05^{* *}$

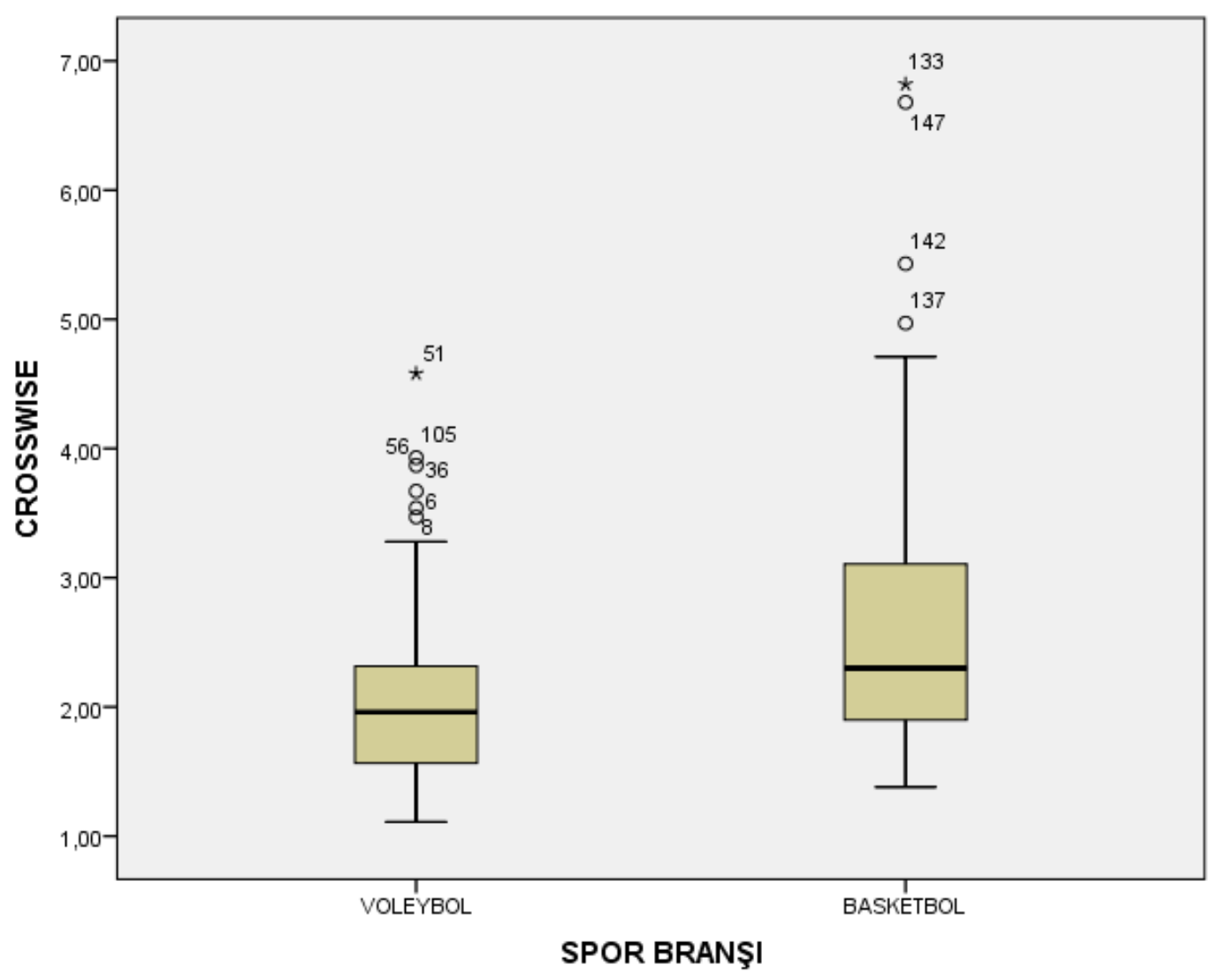

Şekil 3. Sporcuların Branşlara Göre Crosswise Statik Denge Değerleri 


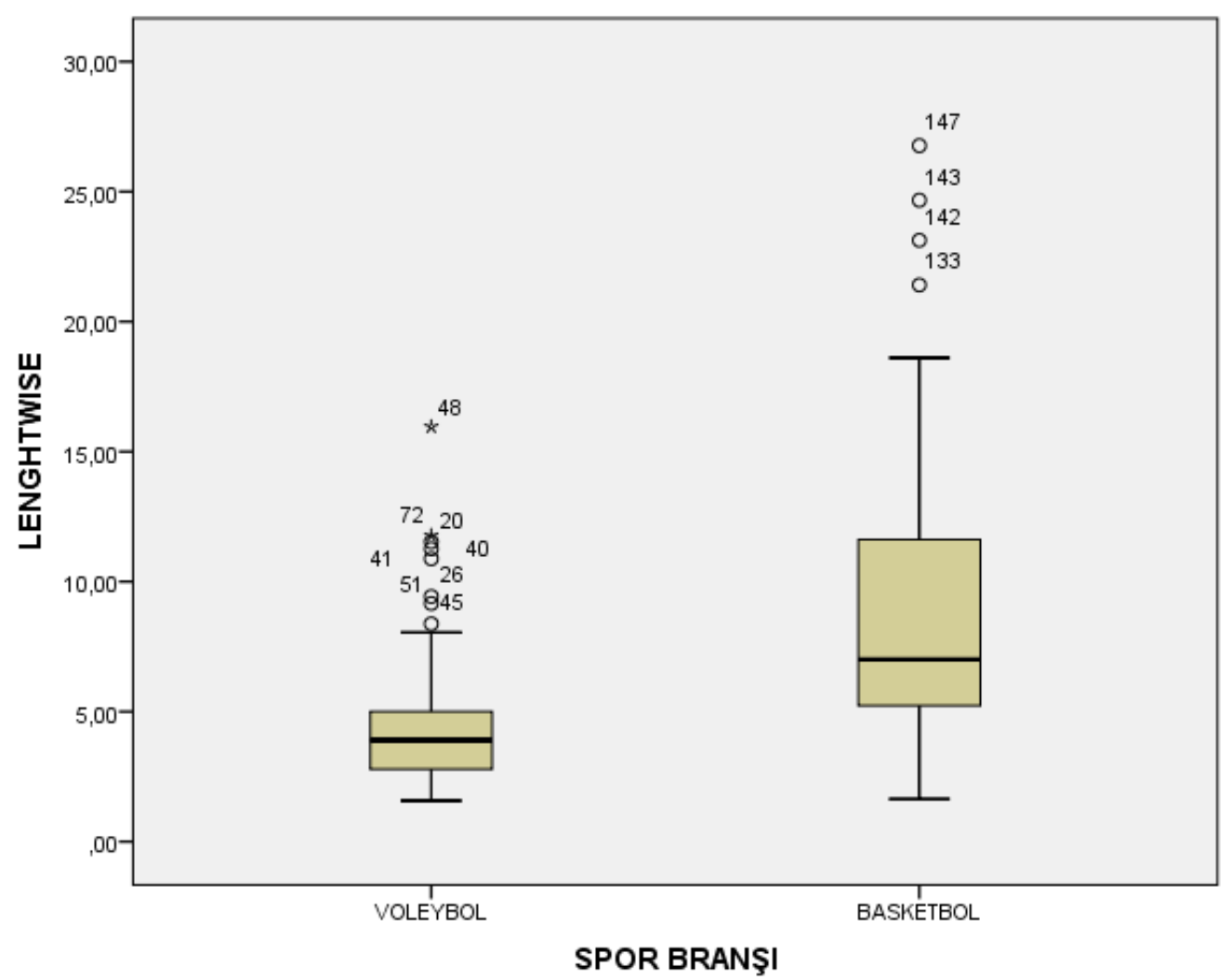

Şekil 4. Sporcuların Branşlara Göre Lengthwise Statik Denge Değerleri

\section{TARTIŞMA ve SONUÇ}

Bu çalışma basketbol ve voleybol spor branşlarında yarışmalara katılan kadın sporcuların denge becerisinin Bass stick lenghtwise ve crosswise statik denge testi ile karşılaştırılması amacıyla yapılmıştır. Çalışmaya, basketbol sporu yapan $108(\% 64,7)$ ve voleybol sporu yapan 59 $(\% 35,3)$ kadın sporcu katılmıştır. Sporcuların yaş ortalamaları 12,38 $\pm 1,46$ yı1, boy 159,32 $\pm 10,41$ cm, ağırlık 50,84 $\pm 10,67 \mathrm{~kg}$, spor yaşı $2,72 \pm 1,48$ yıl, haftalık antrenman saati 4,76 $\pm 2,00$ saat olarak bulunmuştur.

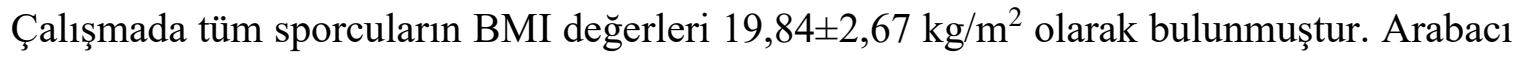
(2008) 15 yaş altı (13,8 $\pm 1,7$ yıl) sporcularda yapmış olduğu çalışmada BMI değerlerini 19,6 $\pm 2,3$ $\mathrm{kg} / \mathrm{m}^{2}$ olarak bulmuştur. Alıcı (2014) yaş ortalamaları 13,96 $\pm 0,79$ olan sporcular üzerine yaptı̆̆

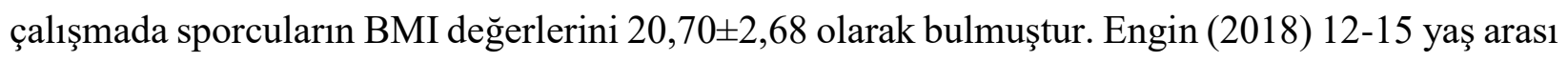

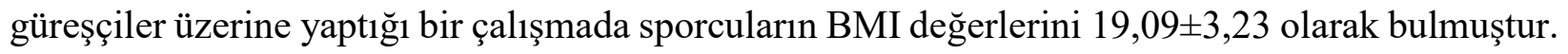
Kocakarın (2018) çocuklara yaptırılan denge egzersizlerinin gelişimlerini incelediği çalışmada 


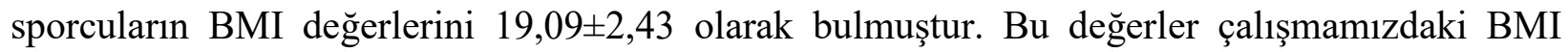
değerlerine yakındır. Çankaya ve ark. (2014) denge geliştirici antrenmanlar üzerine yaptıkları bir çalışmada sporcular ve sedanterlerin BMI değerleri ile denge parametreleri arasında anlamlı bir farklılık bulamamıştır. Yapılan bu çalışma ile bizim çalışmamız benzerlik göstermektedir. Sporcuların branşlara göre spor yaşı ve BMI değerleri açısından anlamlı farklılık saptanmamıştır. Ölçüm alınan grubun yaşlarının birbirine yakın olması bu durumu açıklayabilir.

Sporcuların branşlarına göre lengthwise ve crosswise statik denge ölçüm değerleri arasında anlamlı farklılık bulunmuştur. Her iki statik denge testinde farklılığın basketbol branşından kaynaklandığı görülmüştür. Altavilla, Tafuri ve Raiola (2014) 11-13 yaş arası spor yapan ve spor yapmayan çocukların denge becerilerini karşılaştırdıkları bir çalışmada kapalı göz statik denge testinde basketbol oynayan sporcuların yüzme sporu yapan ve spor yapmayan çocuklardan daha iyi denge becerilerine sahip olduklarını bulmuştur. Tabrizi, Abbasi ve Sarvestani (2013) farklı branşlardaki sporcuların denge becerilerini karşılaştırdıkları bir çalışmada basketbol oynayan sporcuların hentbol ve futsal spor branşlarındaki sporculardan daha iyi statik denge becerisine sahip olduklarını bulmuştur. Bir başka çalışmada ise, Erkmen ve ark. (2007) farklı branşlardaki sporcuların denge becerilerini karşılaştırmış ve basketbol oynayan sporcuların statik denge becerilerinin diğer branşlardaki sporculardan daha iyi olduğunu bulmuştur. Bu sonuçlar ile çalışmamızda elde ettiğimiz sonuçlar birbirine benzemektedir. Ancak, Bressel ve ark. (2007) farklı branşlardaki sporcuların statik dengelerini karşılaştırdıkları çalışmada cimnastik ve futbol branşındaki sporcuların basketbol branşındaki sporculardan daha iyi olduğunu bulmuştur. Cimnastik branşındaki sporcuların denge becerilerinin futbol ve basketbol branşındaki sporculardan daha iyi olmasının sebebi denge aleti üzerine yapılan hareketler gibi çok fazla denge içeren çalışmalar yapmaları hem de yumuşak ve farklı yüzeylerde çalışmalar yapmış olmasından kaynaklandığı düşünülebilir. Ayrıca futbol branşındaki sporcuların denge becerilerinin basketbol branşındaki sporculardan daha iyi olmasının sebebi, futbolun her zaman düz zeminlerde oynanmayıp ıslak, çamurlu vb. farklı zeminlerde oynanması ve oyun yapısından dolayı sporcuların tek ayakla top sürmek, pas, şut ve kafa topuna sıçrayıp tek ayak üzerine düşmek vs. gibi yaptıkları teknik becerileri tek ayak üzerinde yapıyor olmalarından dolayı daha iyi dengeye sahip oldukları düşünülebilir. 
Denge, sportif performansı belirleyen önemli faktörlerden biridir (Muratl1, 2003). Bir cimnastikçinin yaptığı bir hareket sonrasında, dengesini koruyarak yere inmesi, bir futbolcunun aynı anda takım arkadaşları ve rakibinin konumunu kontrol ederek, kendisine gelmekte olan topa göre doğru pozisyonu, dengesini sürdürerek alabilmesi veya bir basketbolcunun rakiple birlikte çıktığı ribaunt sonrasında, topla birlikte yere indiğinde dengesini koruyabilmesi başarılı bir performans için şarttır (Erkmen, 2007). Ayrıca Kılıç (2018) farklı spor branşlarındaki sporcuların denge becerilerini incelediği çalışmada, fiziksel temas içeren sporları yapan sporcuların, fiziksel temas içermeyen sporları yapan sporculara göre daha iyi olduğunu bulmuştur. Buna benzer bir şekilde, çalışmamızda basketbol oynayan sporcuların voleybol oynayan sporculardan statik denge becerileri bakımından daha iyi olduğu bulunmuştur. Bunun sebebi, basketbol branşındaki sporcuların topla daha uzun süre oynaması ve mesafe kat etmesi, ileri-geri, çapraz koşular ve yön değiştirmeler yapması, ani durmalar ve hızlanmalar ile birlikte sıçramalar yapması ve rakip oyuncular ile ikili mücadelelere girerek ayakta kalmaya ve topu kaybetmemeye çalışması voleybol branşındaki sporculardan daha iyi statik dengeye sahip olmasında etkin olabilir. Ancak çalışmanın daha fazla spor branşı, yaş ortalaması büyük ve daha yüksek sayıda katılımcı üzerinde, antropometrik ölçümler dahil edilerek tekrarlanması daha güçlü yorum yapılabilmesini sağlayacaktır.

Sonuç olarak, ikili mücadele ve fiziksel temas içeren sporları yapan sporcuların statik denge becerilerinin fiziksel temas içermeyen sporları yapan sporculardan daha iyi olduğu söylenebilir. Voleybol sporu yapan sporculara normal antrenmanlarına ek olarak farklı yüzeylerde, yumuşak zeminlerde ve fiziksel temasların da bulunduğu denge çalışmaları yapmalarının statik dengelerini geliştirebileceği söylenebilir.

\section{KAYNAKLAR}

Alıcı, Ö. (2014). 13-15 yaş erkek sedanter, hentbolcu ve güreşçilerin bazı fiziksel ve fizyolojik özelliklerinin karşılaştırılması. Niğde Üniversitesi Sosyal Bilimler Enstitüsü, Beden Eğitimi ve Spor Anabilim Dalı, Yayımlanmamış yüksek lisans tezi, Niğde. Tez No: 378647.

Altavilla, G., Tafuri, D., ve Raiola, G. (2014). influence of sports on the control of static balance in physical education at school. Journal of Physical Education and Sport, 14(3), 351. DOI:10.7752/jpes.2014.03053.

Arabacı, R. (2008). 15 Yaş altı kız ve erkek badmintoncularının fiziksel uygunluklarının karşılaştırılması. E-Journal of New World Sciences Academy, 3, 1-2, 5 6. ISSN:1306-3111. 
Türkeri, C., Akyol, E., Büyüktaş, B., Öztürk, B. (2019). Kadın basketbol ve voleybol sporcularının bass stick lenghtwise ve crosswise denge testi karşılaştırması. CBÜ Beden Eğitimi ve Spor Bilimleri Dergisi, 14 (2), 315-325.

Bressel, E., Yonker, J. C., Kras, J. ve Heath, E. M. (2007). Comparison of static and dynamic balance in female collegiate soccer, basketball, and gymnastics aathletes. Journal of Athletic Training, 42(1), 42. PMID: 17597942.

Çakır, E., ve Özbar, N. (2019). Bayan futsal oyuncularında flamingo ve stork denge testinin karşılaştırılması ile kassal kuvvetin testler üzerine etkisi. Gazi Beden Eğitimi ve Spor Bilimleri Dergisi, 24(3), 181-188. ISSN: 1300-2805.

Çankaya, S., Gökmen, B., Musa, Ç. O. N., ve Taşmektepligil, M. (2014). Denge geliştirici özel antrenman uygulamalarının 11 yaş genç erkeklerin reaksiyon zamanları ve vücut kitle indeksi üzerine etkisi. Spor ve Performans Araştırmaları Dergisi, 5(2), 59-67. DOI: 10.17155/spd.07723.

Engin, H. (2018). 12-15 Yaş arası güreşçilerde 8 haftalık denge antrenmanının denge, çeviklik ve sürat performansı üzerine etkisi. Yayımlanmamış yüksek lisans tezi. Ömer Halis Demir Üniversitesi. Niğde. Tez No: 492786.

Erdoğan, C. S. Fatmanur, E. R., İpekoğlu, G., Çolakoğlu, T., Zorba, E., ve Çolakoğlu, F. F. (2017). Farklı denge egzersizlerinin voleybolcularda statik ve dinamik denge performansı üzerine etkileri. Spor ve Performans Araştırmaları Dergisi, 8(1), 11-18. DOI:10.17155/spd.63957.

Erkmen, N., Suveren S., Göktepe A. S., ve Yazıcığlu, K. (2007). Farklı branşlardaki sporcuların denge performanslarının karşılaştırılması. Spormetre Beden Eğitimi ve Spor Bilimleri Dergisi, 3, 115-122. DOI: 10.1501/Sporm_0000000080.

K1lıç, T. R. (2018). Farklı spor branşlarındaki sporcuların denge performans parametrelerinin tanımlayıcı özelliklerinin belirlenmesi. Hacettepe Üniversitesi Sağlık Bilimleri Enstitüsü, Doktora Tezi, Ankara. Tez No: 499162.

Kocakarın, E. (2018). 8-10 Yaş çocuklarda denge egzersizlerinin denge gelişimi üzerine etkileri. Yayımlanmamış yüksek lisans tezi. Celal Bayar Üniversitesi. Manisa. Tez No: 520508.

Muratlı, S.(2003). Çocuk ve Spor. Antrenman Bilimi Yaklaşımıyla. Nobel Yayın Dağıtım. Ankara; 197-219.

Peker, A.T. (2014). Life kinetik antrenmanlarının koordinatif yetenekler üzerine etkisi, Selçuk Üniversitesi Sağlık Bilimleri Enstitüsü, Yayımlanmamış yüksek lisans tezi, Konya. Tez No:410894.

Safrit, M.J. ve Wood, T.M. (1995). Introduction to Measurement in Physical Education and Exercise Science. Usa. ISBN: 0-80167849-8.

Sayın M. (2011). Hareket ve Beceri Öğretimi. Ankara, Spor Yayınevi ve Kitabevi. s: 127-35.

Sökmen, T., ve Arslanoğlu, E. (2013). Judo teknik antrenmanı ve oyunların 8-10 yaş grubu erkek çocukların fiziksel gelişim düzeyleri üzerine etkisi.Spormetre Beden Eğitimi ve Spor Bilimleri Dergisi, 11(2), 73-79. DOI: 10.1501/Sporm_0000000241.

Sucan, S., Yılmaz, A., Can, Y. Ve Süer, C. (2005). Aktif futbol oyuncularının çeşitli denge parametrelerinin değerlendirilmesi. Sağlık Bilimleri Dergisi (Journal of Health Sciences) 14(1) 36-42.

Tabrizi, H. B., Abbasi, A., ve Sarvestani, H. J. (2013). Comparing the static and dynamic balances and their relationship with the anthropometrical characteristics in the athletes of selected sports. Middle-East Journal of Scientific Research, 15(2), 216221. DOI: 10.5829/idosi.mejsr.2013.15.2.7426.

Tetik, S., Koç, M., Atar, Ö., ve Koç, H. (2013). Basketbolcularda statik denge performansı ile oyun değer skalası arasındaki ilişkinin incelenmesi. 6(1), 9-18, ISSN: 1309-1336.

Tükel, Y. (2015). Görme Engelli Judocuların Denge Performanslarının İncelenmesi, Selçuk Üniversitesi Sağlık Bilimleri Enstitüsü, Yayımlanmamış yüksek lisans tezi, Konya. Tez No:422858.

Türkeri, C. (2015). Oniki haftalık salsa dans çalışmalarının vki ve statik dengeye etkisi. Çukurova Üniversitesi Eğitim Fakültesi Dergisi, 44(1), 1-22. DOI: 10.14812/cufej.2015.001.

Zorba, E. ve Saygın, Ö. (2013). Fiziksel Aktivite ve Fiziksel Uygunluk. Ankara: Firat Matbaacılık.

Zorba, E., Yaman, M., Er, F., Suveren, C., Sever, O., Bayrakdar, A., ve Gönülateş, S. (2017). Examination of reaction time and balance relation in children between the ages 9-13. The Online Journal of Recreation and Sport-April, 6(2), 32-39. DOI: 10.22282/ojrs.2017.11. 